\title{
Application of RELUX simulation to investigate energy saving potential from daylighting in a new educational building in UK
}

\author{
Xu Yu, Yuehong Su*, Xin Chen
}

Institute of Sustainable Energy Technology, Department of Architecture and Built Environment, University of Nottingham, University Park, NG7 2RD, UK

* Corresponding author. Tel.: +44 115 8467872; fax: +44 1159513159.

E-mail address: yuehong.su@nottingham.ac.uk

\begin{abstract}
Daylighting is a renewable energy solution for illumination and visual comfort in buildings. Daylighting performance and its induced energy saving largely depend on various factors, including room geometry, window-to-wall ratio, window transmittance, surface reflectance of construction and surrounding obstructers, artificial lighting array, its daylight-related control strategies and so forth. During the last few decades, lighting simulation tools developed quickly to provide researchers and architects a faster and reliable ways to simulate complex lighting environment. The aim of this paper is to deal with a quantitative analysis of annual energy saving potential from daylighting in a real building using various methods. A case study of a newly constructed educational atrium building, Engineering and Science Learning Centre (ESLC) in the University of Nottingham, UK, is presented. Computational analysis using validated lighting simulation tool RELUX will be conducted to simulate the daylighting performance in the selected rooms. Particularly, an economical method to measure window transmittance and interior surface reflectance will be conducted, and the measured results will be input into the simulation software to increase the accuracy of simulation results. The annual energy saving potential in artificial lighting from daylighting is determined by European Standard EN15193 and also estimated using static climate-based Daylight Factor (DF) method and dynamic climate-based Daylight Coefficient (DC) method.
\end{abstract}

Keywords: daylighting, potential energy saving, RELUX simulation, field measurement

\section{Introduction}

The decreasing fossil fuel resources and increasing concentration of greenhouse emission from fossil fuel combustion have begun to cause energy crisis and irreversible damage to atmosphere. As a result, more interests are taken to develop renewable energy or use energy more efficiently [1]. Nondomestic buildings, which are estimated to account for one third of primary energy consumption in USA, has become a major sector where the reduction of energy consumption shall be concerned [2]. 
According to some relevant figures, about 20-30\% of the energy consumption in non-domestic buildings is related to electric lighting in Hong Kong, and this number increases to $25 \%-40 \%$ in USA [3]. In recent decades, some energy saving actions like using energy-efficient lamps, better design strategy to reduce the number of artificial lights have been taken to attain energy saving in nondomestic buildings, but daylighting, which can be harvested through windows into the building and replace the need for artificial lighting to illuminate the interior area, is recognised as a fundamental energy saving design strategy for buildings [4]. Lots of studies show that an integrated daylight and artificial light scheme with proper electric lighting control system can reduce the electricity demand in non-domestic buildings since most of non-domestic buildings operate during daylight hours. Embrechts and Bellegem estimated that a $20-40 \%$ reduction of electricity consumption due to daylighting [5]. A study conducted by Ghisi and Tinker showed that by effectively combining daylight availability with an artificial lighting system in buildings in UK, energy reductions could range from $10.8 \%$ to $44 \%$ [6, 7]. Besides that, results obtained from field measurements and computer simulation analysis on commercial buildings indicated that lighting energy savings varies from $30 \%$ to $77 \%$ using daylight related control systems [8]. Meanwhile, as artificial lighting causes heat gain inside a building, reduced utilisation of artificial lighting can lead to considerable less cooling load and potential for smaller cooling, ventilation and air-conditioning (HVAC) plants [9]. Additionally, daylighting can also contribute to higher productivity and performance for human beings as its colour rendering closely matches human visual response and can provide more comfortable and attractive indoor environment [10]. However, the benefit from daylighting can be penalized by glare and overheating in building interior and therefore reduce the occupants' interests to use the daylight. But this concern can be reduced if proper daylight control can be applied [11].

The potential energy saving through daylighting is mainly accomplished by the application of daylight-linked artificial lighting control, which can adjust the artificial lighting output in accordance to the penetrated daylighting through windows so that the target interior illuminance level could be maintained. However, the amount of energy saving that lighting control can achieve varies in different literatures, for example, Szerman estimated that $70 \%$ of lighting electricity could be saved from introducing daylight into buildings while Zeguers evaluated the simulation result of $20 \%$ lighting energy saving [12]. The main reason for this difference can be explained by many factors including site characteristics, building geometric parameters, window size or type, static or dynamic shading device, shading effects from nearby buildings, lighting control strategies and so forth, one 
change in these factors could result in difference in energy saving values [13]. Of all the factors, the choice of daylight-related light control systems may give significant impact on the amount of potential savings. High frequency dimming control and on-off control are two commonly used lighting control system in day-lit buildings [14], both of them are achieved by photosensor, which monitors the daylight level and sends the signal to dimmable electronic ballast, thus the luminous flux output of artificial lightings can be adjusted. Studies showed that on-off control is able to save more energy in areas with high daylight factor than high frequency dimming control while more electric energy saving can be obtained from high frequency dimming control where daylight factor or required service illuminance level are low [2].

In order to help architects and building developers to choose proper daylight strategies so that both comfortable built environment and reduced electric lighting energy demand can be achieved, a growing number of lighting simulation software have been developed around the world in recent years. According to the figure from Reinhart and Fitz, by 2004, about $80 \%$ of the daylight-related researches were accomplished with the help of simulation software [15]. Two simulation algorithms are normally used, saying, raytracing and radiosity. However, the simulation results are affected by the choice of artificial sky models, most of the simulation tools use standard CIE sky models, which obviously have a difference from the real sky condition [16]; another factor to influence the daylight simulation result is the estimation of optical properties of room components like surface reflectance and window transmittance [17], Mardaljevic found the significant effects by errors from reflectance estimating of surrounding surfaces and $\mathrm{Li}$ et al also indicated the influence of furniture reflectance on the accuracy of simulated results $[18,19]$. Due to lack of reliable and transparent validation studies, the range of errors in the simulation results from various computer programs are still difficult to be estimated [20].

\section{Objectives and Case Study}

\subsection{Objectives}

This is a case study on the newly constructed educational building: Engineering and Science Learning Centre (ESLC) in the University of Nottingham, UK, and it will focus on three main objectives. Firstly, a novel and economical method using photometric integrating box will be introduced to provide reliable room parameters such as window transmittance and 
ceiling/wall/floor/furniture reflectance for accurate computational daylighting simulation. Then a relatively new daylighting simulation software RELUX will be used to simulate daylighting and artificial lighting performance in some typical side-lit rooms in the ESLC and the simulation results will be validated through field measurement. Lastly and most importantly, the validated simulation and field measurement results will be used to estimate annual energy saving potential in one of selected rooms using Daylight Factor (DF) and Daylight Coefficient (DC) methods. Meanwhile, the calculation of energy saving potential will not only consider the daylight availability but also take the influence of artificial lighting into account. It should be noted that the influence of reduced artificial lighting output on heating and cooling load will not be discussed in this study.

\subsection{Case Study}

As presented in Figure 1a, the Engineering and Science Learning Centre (No.54) stands adjacent to Coates (No.36), Pope (No.27) and Chemistry Building (No. 28) in the University of Nottingham, UK. It is a 3500 square meter horseshoe-shaped three-floor building with a large central atrium covered by a high transparent ETFE (Ethylene TetrafluoroEthylene Co-Polymer) roof. This newly constructed educational building provides a modern learning environment for students and academic staffs by offering a variety of facilities, including number of seminar rooms, lecture rooms, offices, computer suites and social areas. The orientation of this building is Northeast/Southwest. Figure 2 demonstrates interior and exterior view of the building. It can be observed that it is a daylightefficient building since both large side-windows and atrium can offer great amount of daylighting into the building, the static external shading can act as shading device so that both risks of glare and excessive heat gain can be reduced. Due to its state of the art, high energy efficiency and sustainable design, this building has achieved a BREEAM Excellent rating [21]. In order to evaluate the influence of various parameters on potential energy saving in different rooms in the ESLC, four daylit rooms on Level B (Figure $\mathbf{1 b}$ ) with different orientations and room geometry characteristics were selected and illustrated in Table 1, their distance from window façade to surrounding buildings are also listed. The manufacturing data for artificial lightings were also listed in Table 2. 

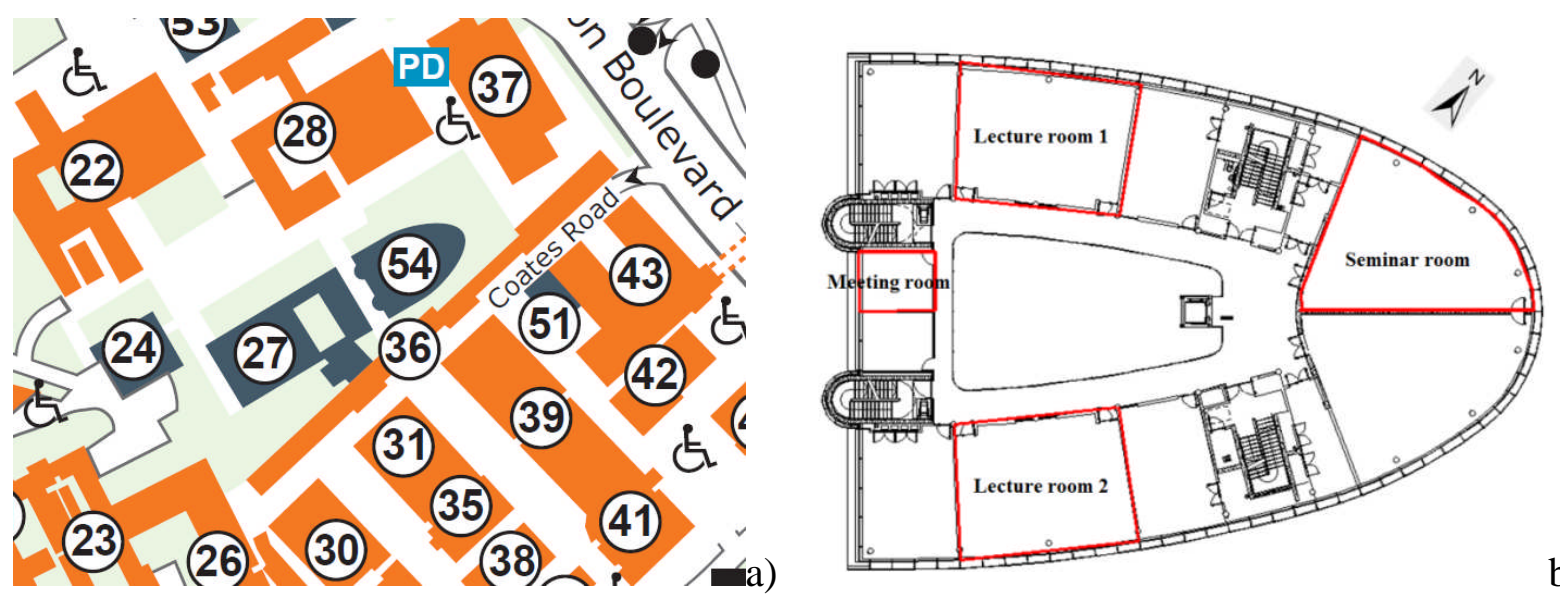

Figure 1: a) Location and surroundings of the ESLC (No.54); b) layout of four selected rooms

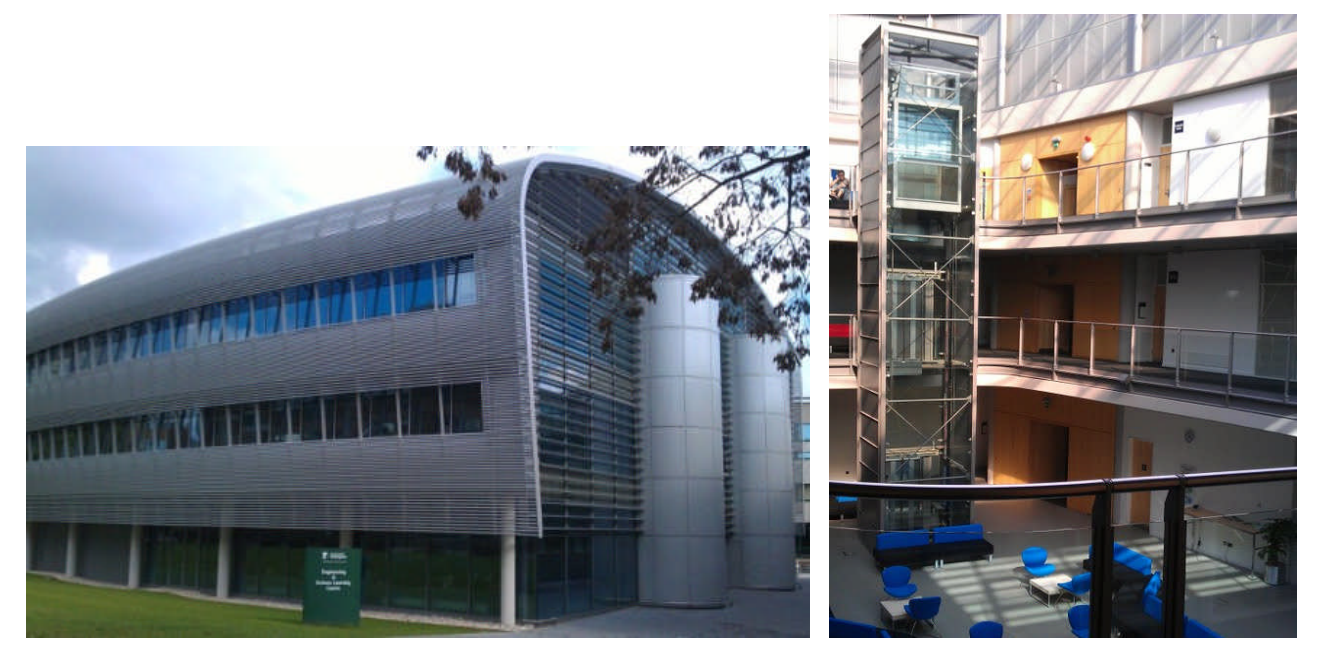

Figure 2: Exterior and interior view of the Engineering and Science Learning Centre (ESLC)

Table 1: Geometrical parameters of the selected rooms

\begin{tabular}{llllll}
\hline Room & $\begin{array}{l}\text { Window } \\
\text { Orientation }\end{array}$ & $\begin{array}{l}\text { Window Area } \\
\left.\mathbf{( m}^{\mathbf{2}}\right)\end{array}$ & $\begin{array}{l}\text { Window-to- } \\
\text { floor Ratio }\end{array}$ & $\begin{array}{l}\text { Window-to- } \\
\text { wall Ratio }\end{array}$ & $\begin{array}{l}\text { Distance to } \\
\text { nearby } \\
\text { buildings (m) }\end{array}$ \\
\hline Lecture Room 1 & Northwest & 20.7 & 0.19 & 0.45 & 16 \\
Lecture Room 2 & Southeast & 20.7 & 0.19 & 0.45 & 9 \\
Seminar Room & North & 31.0 & 0.23 & 0.45 & 30 \\
Meeting Room & Southwest & 12.5 & 0.85 & 0.83 & 10 \\
\hline
\end{tabular}


Table 2: Summary of artificial lighting specifications

\begin{tabular}{lll}
\hline Luminaire & Manufacturer & Thorn Lighting \\
\cline { 2 - 3 } Dype & Luminaire efficiency & $87.5 \%$ \\
Luminaire efficacy & $83.411 \mathrm{~m} / \mathrm{W}$ \\
Total system power & $75 \mathrm{~W}$ \\
& Length & $1510 \mathrm{~mm}$ \\
& Width & $164 \mathrm{~mm}$ \\
& Height & $52 \mathrm{~mm}$ \\
\hline Lamp Data & Manufacturer & Ge LongLast Lighting \\
\cline { 2 - 3 } & Type & Linear Fluorescent Lamps \\
& Quantity & 2 per luminaire \\
& Power per lamp & $35 \mathrm{~W}$ \\
& Color Temperature & $6500 \mathrm{~K}$ \\
& Luminous flux per lamp & $36501 \mathrm{~m}$ \\
\hline
\end{tabular}

\section{Methodology}

\subsection{Measurement of Window Transmittance and Surface Reflectance}

Window transmittance is one of the most important factors for the day-lit room as it determines the percentage of daylight penetrating from outside into the interior space. It can be defined by the ratio of illuminance on the inside of a window to the outside. Moreover, the surface reflectance of wall, ceiling, floor and furniture is another important factor to determine the daylighting level, especially in deeper part of the room. Therefore, a precise estimation of above two factors is essential to accurate estimation of daylighting performance. For this case study, the data for window transmittance and surface reflectance are unavailable from the building constructor. Therefore, a field measurement is necessary to get the first-hand data. Recently, there are lots of commercial products for the measurement of transmittance or reflectance, but the expense of these meters is high. In this study, a simple and economical device called the photometric integrating box was construed to measure the value of window transmittance and surface reflectance. 


\subsubsection{Window transmittance}

Figure 3 shows the configuration of the photometric integrating box used for measurement. The dimension of the box is $0.3 \times 0.3 \times 0.3 \mathrm{~m}^{3}$ and it was made of plywood. The inner surface of the box was painted matt white with reflectance of 0.8-0.9 so that most of the light can be reflected. For the top panel, there is a circular aperture with diameter of $50 \mathrm{~mm}$ so that light can penetrate into the box. An internal illuminance sensor was attached to the inner side of top panel and pointed downward to measure the reflected light. Meanwhile, another sensor was used to measure the outside illuminance. All the sensors are Skye Instrument SKL310 illuminance sensors (typically uncertainty $< \pm 3 \%$ ) and connected to Skye Instrument Datahog 2 Data Logger. The calibration between the sensors had been done in preparation.
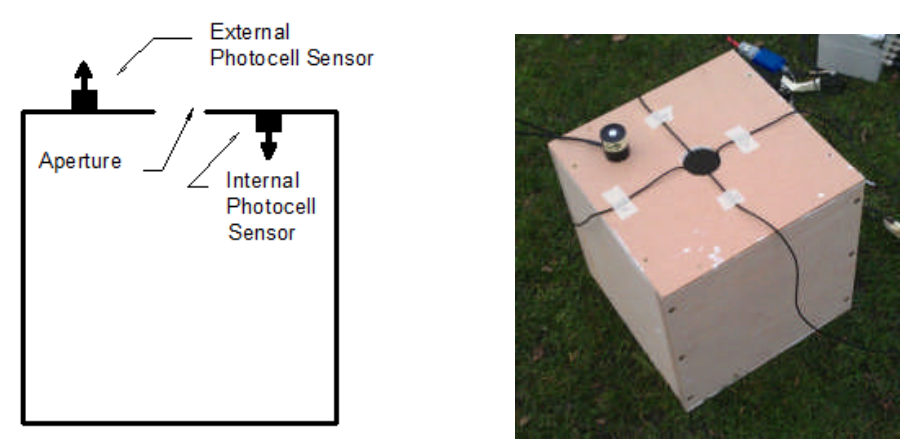

Figure 3: Configuration and image of the photometric integrating box

First of all, a concept of conversion factor was introduced to reflect the ratio of the illuminance at the internal sensor position to the lumen entering the box aperture, which can be expressed by Equation 1.
$\boldsymbol{C F}_{\text {box }}=\frac{E_{\text {in }}}{F_{\text {aperture }}}=\frac{E_{\text {in }}}{\pi r^{2} E_{\text {out }}}$

$$
C F_{b o x}{ }^{*}=C F_{b o x} \cdot \pi r^{2}=\frac{E_{\text {in }}}{E_{\text {aut }}}
$$

where $\boldsymbol{C F}_{\text {box }}$ is the conversion factor of the box, $\boldsymbol{E}_{\text {in }}$ is the illuminance at the internal sensor point, $\boldsymbol{F}_{\text {aperture }}$ is the lumen input to the box, $\boldsymbol{r}$ is the radius of the aperture and $\boldsymbol{E}_{\text {out }}$ is the external horizontal global illuminance at the aperture, $\boldsymbol{C F}_{\text {box }}{ }^{*}$ is the advanced conversion factor. 
Joel Callow found that the conversion factor was constant for a fixed box geometry and surface reflectance regardless of sky condition [22]. Before measuring the window transmittance, the calibration process needs to be carried out to find the conversion factor for this integrating box.

After the process of determining the conversion factor, the aperture of the box was attached against the target window glazing (Figure 4), the illuminance values at the internal and external sensor positions, saying $\boldsymbol{E}_{\text {in,with glazing }}$ and $\boldsymbol{E}_{\text {out,with glazing, }}$, were recorded every minute for a period of 30 minutes, using the Skye Instrument Datahog 2 data logger. The recorded value could be input into Equation 2 to find the window transmittance. The value for $\boldsymbol{C F}_{\boldsymbol{b o x}}{ }^{*}$ was pre-determined.

$T=\frac{F_{\text {glazing back }}}{F_{\text {glazing front }}}=\frac{E_{\text {in with glazing }} / C F_{\text {box }}}{E_{\text {out with glazing }} * \pi r^{2}}=\frac{E_{\text {in,with glazing }}}{E_{\text {out with glazing }}} * \frac{1}{C F_{\text {box }}{ }^{*}}$

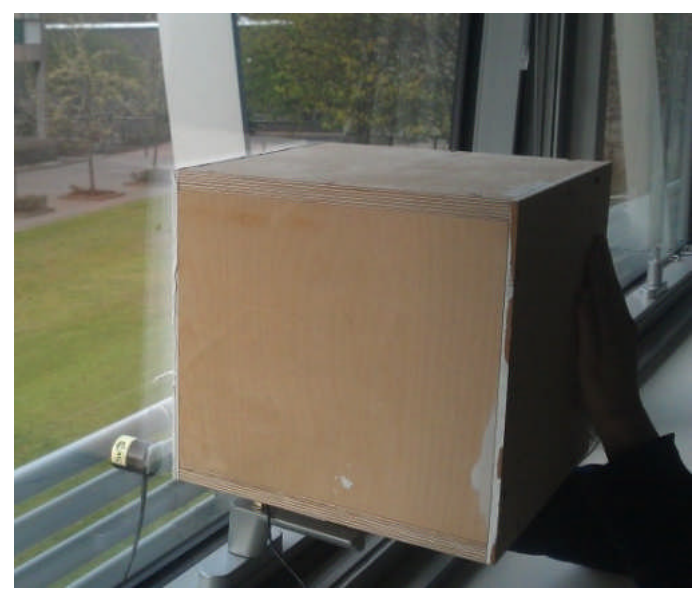

Figure 4: Field measurement of window transmittance

\subsubsection{Surface reflectance}

The device to estimate the surface reflectance of room construction materials was similar to that of window transmittance (see Figure 5), but the source of light was replaced by a compact fluorescent lamp with a fixed luminous output, and was contained in Box 1, all the inner surfaces of Box 1 was painted matt white. The main purpose of doing this is to provide a relatively stable light source so that the amount of light penetrating through the aperture between Box 1 and 2 could be constant. The illuminance on the bottom of Box 1 was monitored by illuminance sensor 1, which faces towards the light source, saying $\mathrm{E}_{1}$. Another difference is that the bottom panel of Box 2 was removed and 
attached against the target material while other surfaces of Box 2 were painted matt black so that no light could be reflected except the target material on the bottom. On the top panel of Box 2, another illuminance sensor directing right downwards was installed to measure the illuminance level of reflected light by the target surface, saying $\mathrm{E}_{2}$. Theoretically, the amount of light penetration into Box 2 is constant and can only be reflected by the target surface on the bottom of Box 2, the reflectance of the target material may be the only factor that influences the value of $\mathrm{E}_{2}$. Therefore, there should be a correlation between the reflectance of the target surface and the ratio of $\boldsymbol{E}_{2}$ to $\boldsymbol{E}_{\boldsymbol{1}}$, i.e. $\boldsymbol{E}_{2} / \boldsymbol{E}_{1}$.

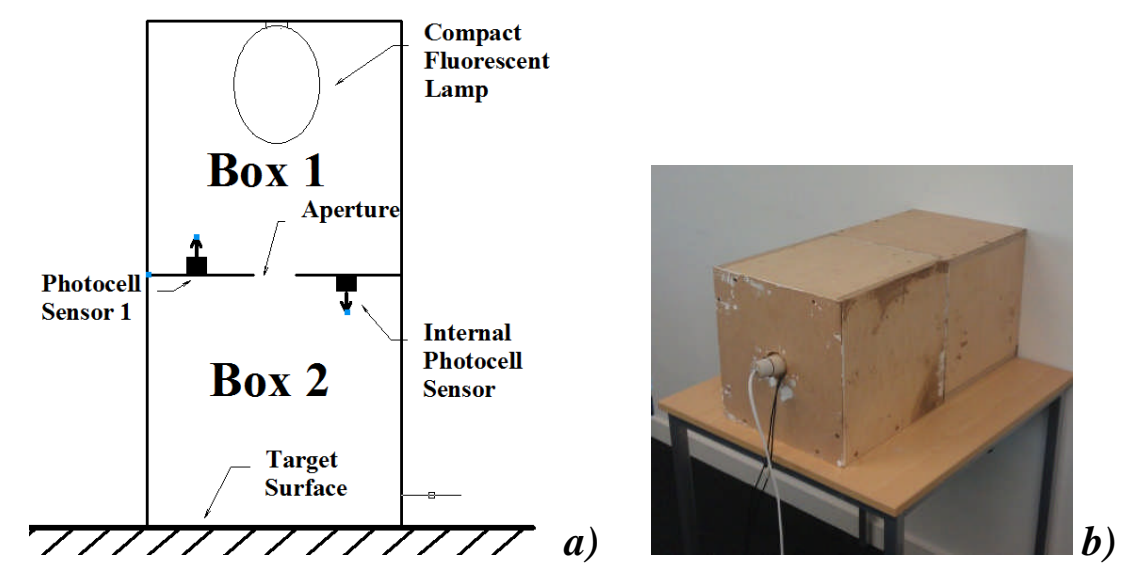

Figure 5: Configuration and image of the integrating box for wall reflectance measurement

In order to verify the hypothesis mentioned above, this simple measuring apparatus was simulated with Radiance, aiming to find the relationship between surface reflectance $\boldsymbol{\xi}$ and the ratio of two light sensor readings $\boldsymbol{E}_{2} / \boldsymbol{E}_{\boldsymbol{1}}$. Radiance was a backward ray tracing simulation tool and developed by the Lawrence Berkeley Lab, in which the path of the ray is traced from the measure points or eyes back to the light source. This simulation software was regarded as reliable lighting simulation software as it can predict light performance with a high degree of accuracy in wide range of conditions. Although Radiance has many "non-attractive" features and has not been developed in the past few years, it continues gained the favour by lighting researchers [15], and most of the newly developed lighting simulation software were based on the simulation theory of Radiance. The great convenience of Desktop Radiance is that it can use CAD or Ecotect as an operational platform to build 3D models with material properties and create realistic picture of the modelled environment [1]. Another reason to use Desktop Radiance is that it offers freedom in specifying the position and direction of illuminance points for this small size measurement apparatus. 
During the computational simulation, only the surface reflectance of the base board of Box 2 was changed from $0 \%$ to $100 \%$ with interval of 5\%, the simulation results in Figure 6 indicated that there seems to be linear relationship between the reflectance and the ratio of $\boldsymbol{E}_{2}$ to $\boldsymbol{E}_{1}$, i.e. $\boldsymbol{E}_{2} / \boldsymbol{E}_{\boldsymbol{1}}$. And it has been validated by some reference materials. Therefore, the hypothesis seems to be acceptable and the reflectance of target material of wall/ceiling/floor/table surface can be estimated according the value of $E_{2} / E_{1}$.

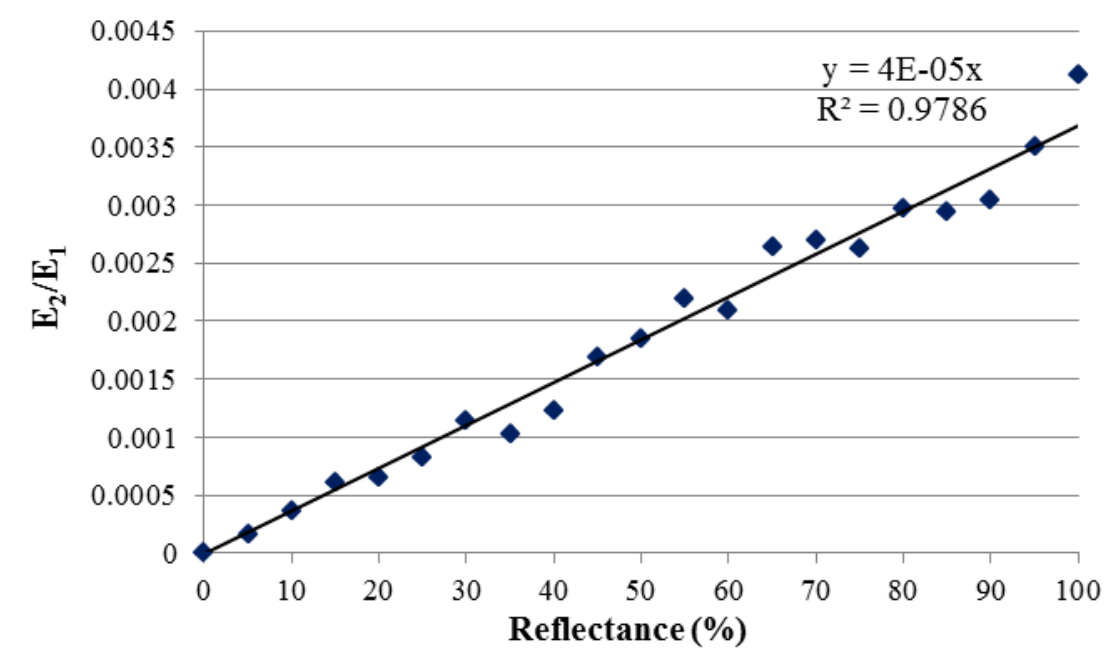

Figure 6: Simulated correlation between $E_{2} / E_{1}$ and surface reflectance

\subsection{RELUX Simulation}

RELUX Suite is a freeware developed by RELUX Informatik AG in Switzerland and supported by a number of luminaire, sensor and lamp manufacturers [23]. It is a simple but usable lighting simulation tool, where visual design elements of a building including materials, furnishing and colour can be simulated; all of the above element can influence real light distribution. By using this useful graphical tool, simulations of artificial light and daylighting are practicable. In 2006, a validation for two lighting simulation software under 32 different scenarios was conducted as part of the IEA SHC Task 31. RELUX was one of the lighting simulation tools and its results showed good agreement with the analytical estimation under majority of test cases [20]. Moreover, another attracting feature of RELUX is that it links with lighting manufacturers' databases and can be easily imported to the simulation.

In this case study, daylighting availability in each selected room might be indicated by the wellknown Daylight Factor (DF), which by definition is the ratio of the internal illuminance to the 
outdoor illuminance simultaneously available on the horizontal plane from the whole of an unobstructed CIE overcast sky [24]. The distribution of artificial lighting is also simulated and represented by contour graph in RELUX. Some crucial room parameters required for RELUX simulation setup were either from field measurement or recommended by the Chartered Institution of Building Services Engineers (CIBSE) [25].

The models of the selected rooms in Table 1 were built in RELUX as well as the surrounding buildings. With the help of EasyLux function in RELUX, the luminaires are distributed in the rooms and suspended on the ceiling in a distance of $0.5 \mathrm{~m}$, placing parallel to the windows. The number, location and specification of luminaire are as same as the real room. The interior furniture and decoration could also be added into the room model, see Figure 7. The reference measuring plane of each room was manually set with $0.5 \mathrm{~m}$ from the wall and $0.75 \mathrm{~m}$ in height as the real working plane height. The reference measuring plane was divided into several grids with sizing of $0.5 \mathrm{~m} * 0.5 \mathrm{~m}$ in order to get more precise results. The CIE Overcast sky was selected to obtain the Daylight Factor value.

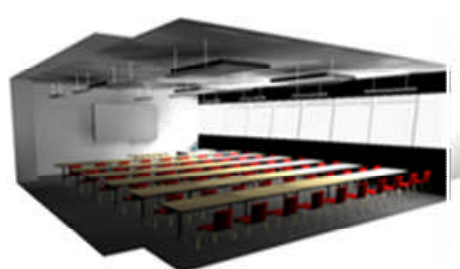

Lecture room 1

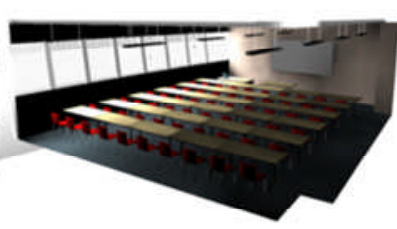

Lecture room 2

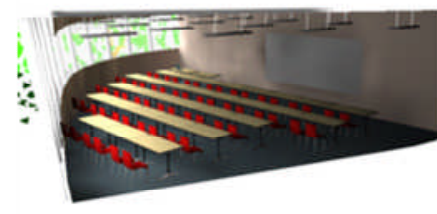

Seminar room

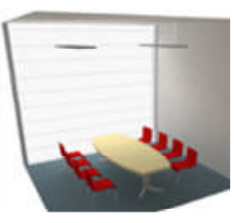

Meeting room

Figure 7: Models of selected rooms in RELUX

\subsection{Field measurement}

To have a direct knowledge of the selected rooms, series field measurements of the selected rooms were conducted. It includes the measuring of Daylight Factor, the investigation of artificial light control scheme, and the evaluation of correlation between the light luminous output and energy consumption. All the measurements were based on the Lecture Room 1 as all the selected rooms share the same artificial lighting characteristics.

\subsubsection{Daylight Factor (DF) measurement}

The main purpose of this measurement is to validate the DF result of the RELUX simulation. The Lecture Room 1 was selected, three groups of measurements were taken to represent daylight 
performance in the front part, in the middle part and in the back part of the room separately (Figure $8)$. For each group, five internal sensors and one external sensor were used to measure internal and external illuminance simultaneously under overcast sky. For the internal illuminance, all five SKL310 illuminance sensors were put on the desk level $(0.75 \mathrm{~m})$, on a line perpendicular to the window façade. The first sensor was set $0.5 \mathrm{~m}$ away from the window, which was same as the grid set-up in RELUX, then the rest four sensors were evenly distributed, the distance was therefore $1.8 \mathrm{~m}$. As to the external illuminance, the measurement was taken in an open outdoor area without any nearby obstacles. According to the definition of daylight factor, the DF for selected measuring points was the ratio of internal illuminance to external illuminance. Three groups of measurements were taken to represent daylight performance in the front part, in the middle part and in the back part of the room separately (Figure 8). All three measurement groups were under relatively same overcast sky and each lasted for one hour.
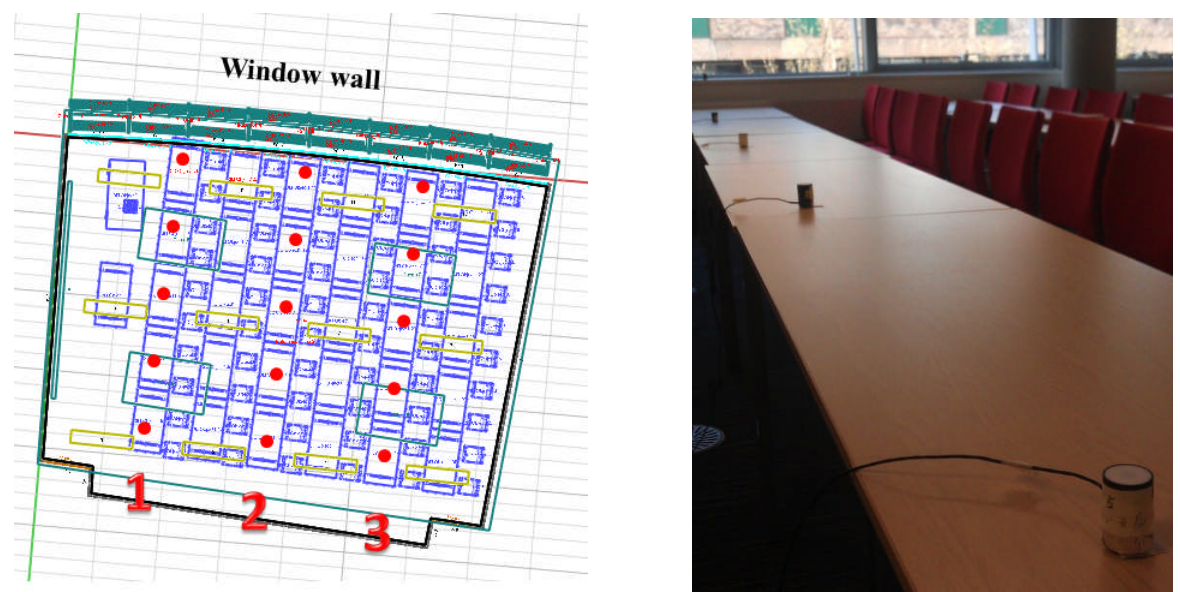

Figure 8: Arrangement of the internal illuminance sensors for daylighting measurement

The measuring equipment are illustrated in Figure 9; a Skye Instrument Datahog 2 data taker, which was attached by 5 Skye Instrument SKL310 illuminance sensors (typically uncertainty $< \pm 3 \%$ ) was used to capture and measure the interior illuminance level (lux) of the room simultaneously with interval of 10 seconds and averaged over 1 minute. Meanwhile, a hand held Hagner Luxmeter E2-X (uncertainty $< \pm 3 \%$ ) was applied to measure the external illuminance level simultaneously with the internal ones. The pre-calibration between internal and external sensors was done before the measurement. 

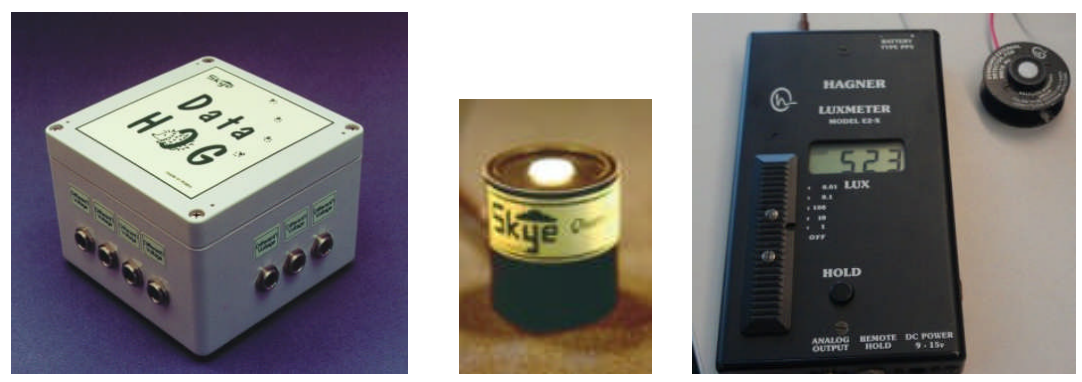

Figure 9: Skye Datahog 2 Data Taker, Light Sensor and Handhold Luxmeter

\subsubsection{Artificial lighting measurement}

The field measurement for artificial lighting performance was conducted at night time so that it would not be influenced by daylight. The measuring equipment was as same as that of daylighting measurement, but the selection of measuring points was slightly different. As shown in Figure 10, these measuring points were selected in order to represent the lighting levels in different parts of the room, according to different relative distance to the nearest lighting source. Therefore, points under the middle of one lighting source, under the middle between two lighting sources and under the edge of a lighting source were selected and each group of measuring points were on a line perpendicular to the windows. Before the measurement, all the blinds were fully closed and indoor illuminance with artificial lights off were measured to ensure that the illuminance levels are 0 lux.

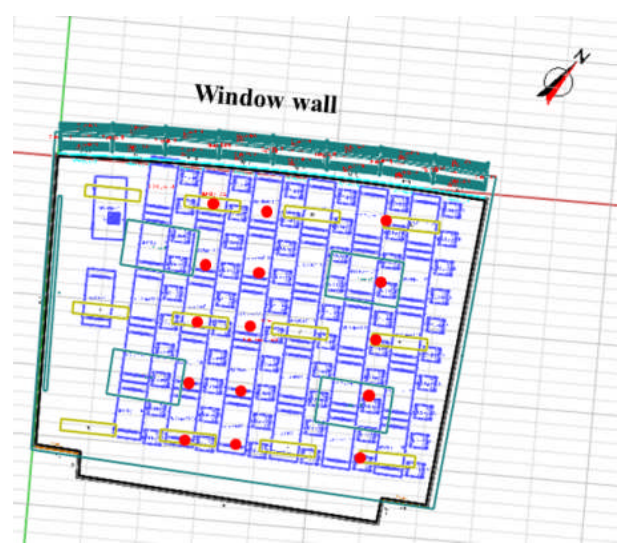

Figure 10: Arrangement of the internal illuminance sensors for artificial lighting measurement 


\subsubsection{Artificial light output versus energy consumption}

In a day-lit space, artificial lighting energy consumption can be reduced if appropriate lighting control system can be used according to its interior daylight level, lighting control can also provide user convenience and an improved lighting environment. Therefore, choosing a proper type of lighting control is essential to daylighting induced energy saving. Littlefair [26] recommended different types of lighting controls for various space classifications. It was observed that the existing artificial lighting control system for selected rooms was high frequency dimming control. This is a close loop control system, and is accomplished by the dimmable electronic ballasts, by which the light output of luminaries can be adjusted continuously according to the indoor daylight availability monitored by photosensor. Thus the required illuminance level can be maintained. However, it is not possible to dim the light output to total extinction for the high frequency dimming control [27]. Due to lack of equipment to measure light output and its induced energy consumption, the correlation between fraction of light output and energy consumption was quoted from previous research and illustrated in Figure 11. It was a linear relationship with the minimum light output $\boldsymbol{F}_{\boldsymbol{L}}$ of $5 \%$ and corresponding power consumption $\boldsymbol{F}_{\boldsymbol{P}}$ of $20 \%$. As a result, a function to represent this relationship can be summarized in Equation 3.

$$
F_{P}=0.84 F_{L}+0.16\left(F_{L}>0.05\right)
$$

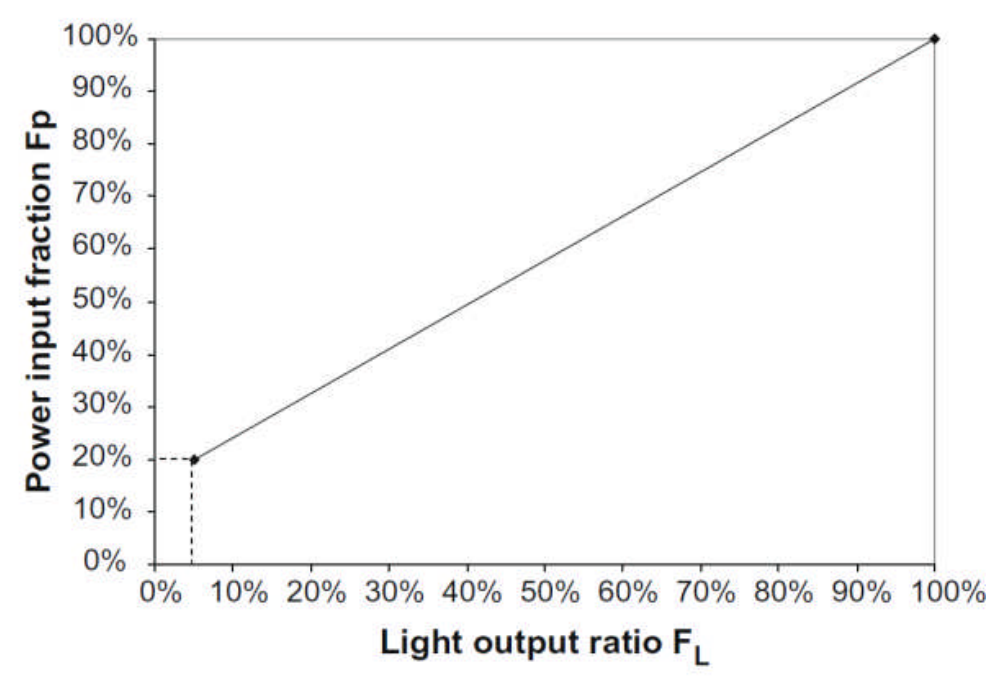

Figure 11: Correlation between light output ratio and power input ratio for an ideal high frequency dimming lighting control [27] 


\section{Results}

\subsection{Window Transmittance and Material Reflectance}

For the measurement of the window transmittance, the conversion factor for the integrating box was firstly determined and illustrated in Figure 12. The result shows a good agreement with previous study by Callow [22], that is, for a certain integrating box with fixed aperture area and internal reflectance, there should be a fixed value for the conversion factor, regardless of external illuminance. For the box we used for the measurement, the value for conversion factor is 0.0279 .

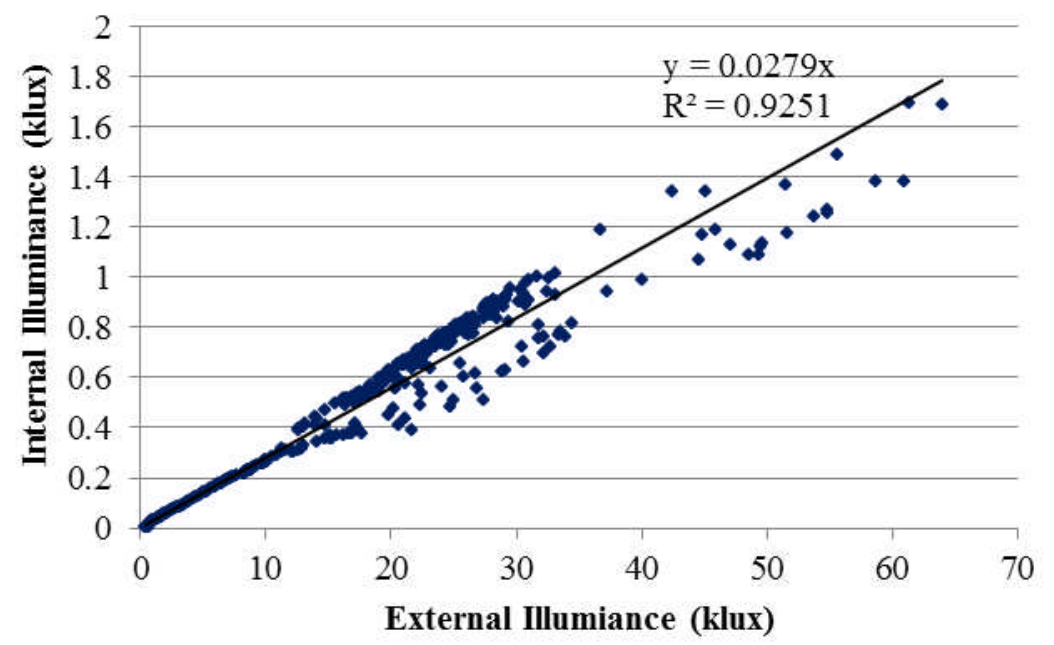

Figure 12: Conversion factor for the integrating box with the opening diameter of $50 \mathrm{~mm}$

When the aperture of the box was covered by the target window in selected room, a new ratio of the external to internal illuminance can be obtained and showed in Figure 13, which is 0.0241 . According to Equation 2, the transmittance of target window is 0.767 . 


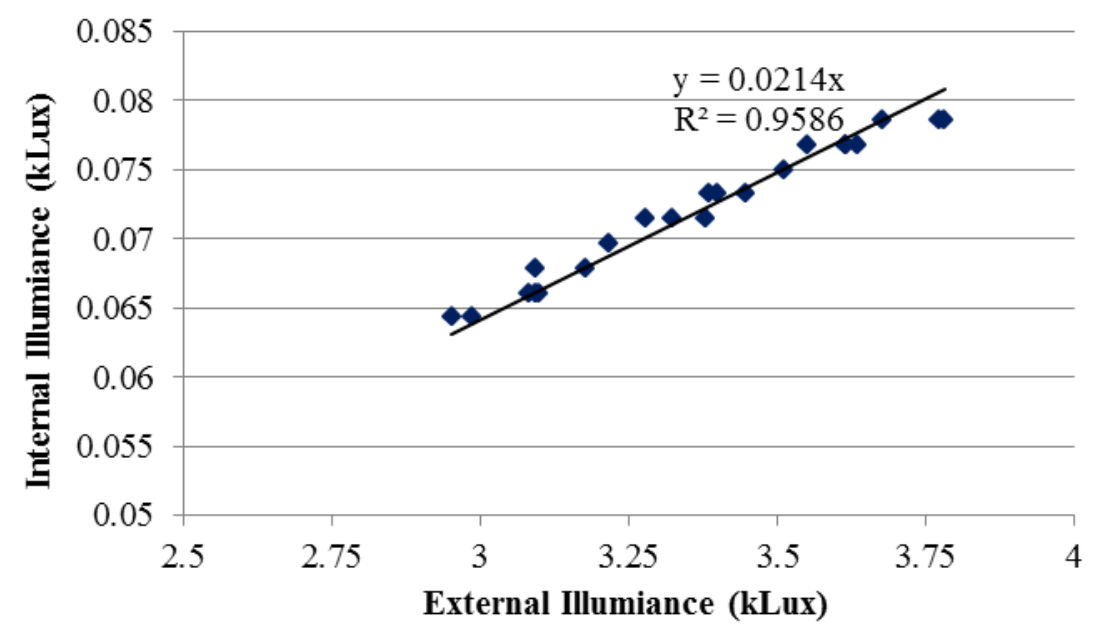

Figure 13: Sample of data from window transmittance measurement

According to the results from Figure 6, the material surface reflectance could be obtained according the measured value of $\boldsymbol{E}_{2} / \boldsymbol{E}_{1}$. The modified integrating box in Figure 5 was attached to various room surface and the results are summarised in Table 3. These results were comparable to the widely accepted value of wall/ceiling/floor reflectance, saying 0.7/0.5/0.3 [4]. The measured value was close to the widely accepted value; therefore, this simple method to measure the surface reflectance would be practicable.

Table 3: Estimated material surface reflectance

\begin{tabular}{lllll}
\hline & Wall & Ceiling & Table surface & Floor \\
\hline Measured $\mathbf{E}_{2} / \mathbf{E}_{1}$ & 0.0022 & 0.0025 & 0.0019 & 0.0005 \\
Reflectance (\%) & $66 \%$ & $70 \%$ & $52 \%$ & $12 \%$ \\
\hline
\end{tabular}

\subsection{Daylight Factor from simulation and field measurement}

The field measurement provided a first-hand data for simulation, all the relevant input data for simulation is concluded in Table 4. The simulated Daylight Factor results for the four selected rooms under CIE overcast sky condition is presented in Figure 14. Generally, it can be observed that the maximum Daylight Factor value in every room is found near the window, after that, this value drops dramatically as the distance from the window increases. In the deeper part of the room, the Daylight Factor level tends to be constant. Specifically, Lecture Room 1 and 2 have the same room dimension but the DF in Lecture Room 1 is slightly higher than that of Room 2, this difference might be caused 
by the obstruction effect from surrounding buildings, the surrounding building of Room 2 is closer than that of Room 1; moreover, the daylighting performance in Meeting Room is much better than other rooms, this is mainly owing to its relatively higher window-to-wall ratio and smaller distance between window facade and back wall; additionally, the Seminar Room has better daylighting performance than other two lecture rooms; this may be caused by its relatively larger window-tofloor area ratio. Meanwhile, it is recommended by the CIBSE Guide that the artificial lighting should be lit in the space where the average DF is less than 2\% [28]. According to this, only Meeting Room can have adequate daylight availability and other rooms have to be artificially illuminated especially under the overcast sky condition in order to maintain adequate lighting level for work and achieve visual comfort, especially when the outdoor illuminance is low.

Table 4: Summary input for simulation

\begin{tabular}{ll}
\hline Room Parameters & Value \\
\hline Ceiling/Wall/Floor/Table Reflectance values & $0.7 / 0.66 / 0.12 / 0.52$ \\
Window Transmittance & 0.767 \\
Working Plane Height & $750 \mathrm{~mm}$ \\
Required Indoor Illuminance (at working plane height ) & $5001 \mathrm{ux}$ \\
Building Occupation Schedule & $8: 00 \mathrm{am}$ to 18:00pm \\
Sky condition & CIE Overcast Sky \\
\hline
\end{tabular}

On the other hand, the Daylight Factor from field measurement for three parts of Lecture Room 1 is shown in Figure 15, it can be seen that the general characteristics and changing trends of daylight distribution are similar for all parts of the room. However, in the area of $1-4 \mathrm{~m}$ away from the window, the DF value for front and rear part of the room is higher than that of the middle part, this difference shows the effect of reflected daylight on the daylighting distribution, the front and rear part of the room can benefit from reflection by the front and rear wall, while this benefit for the middle part is low. But in general, the distance from the window seems to be the major influential factor on daylighting distribution.

Figure 16 compares the simulated DF value from RELUX and averaged DF value from field measurement. It can be found that the RELUX simulation gives a much higher DF within the $4 \mathrm{~m}$ distance from the window than the result from field measurement, and the deviation drops in the rear part of the room. The difference of the results from software simulation and field measurement is 
mainly caused by three reasons; firstly, the RELUX simulation does not consider the thickness of the building façade, which makes the simulated illuminance level near the window higher than the reality. Secondly, the setup for surface reflectance of surrounding buildings, external ground reflectance and external shading device in simulation may not as same as the existing condition. And finally, although the sky condition during field measurement is absolute overcast sky, but it may be still not as same as standard CIE overcast sky in RELUX. Other errors like measuring equipment error may also be counted. However, the deviation between these two results is within the general agreement of acceptable value, saying $20 \%$ [29, 30]. Therefore, the RELUX is reliable to provide daylight factor value for estimating the energy saving in the later part of the paper.
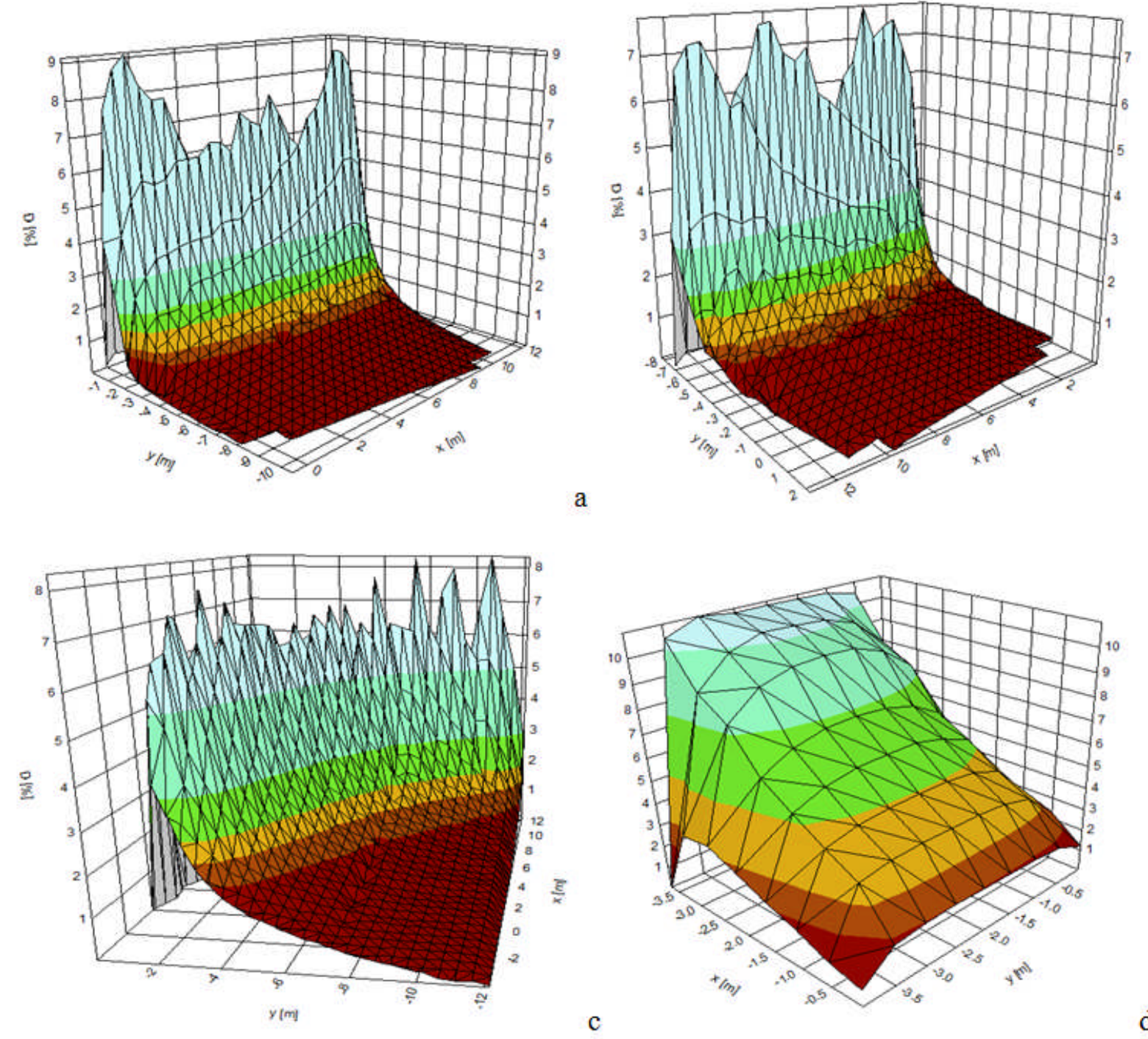

Figure 14: 3D contour line for simulated Daylight Factor a ) Lecture Room 1; b ) Lecture Room 2; c) Seminar Room; d) Meeting Room 


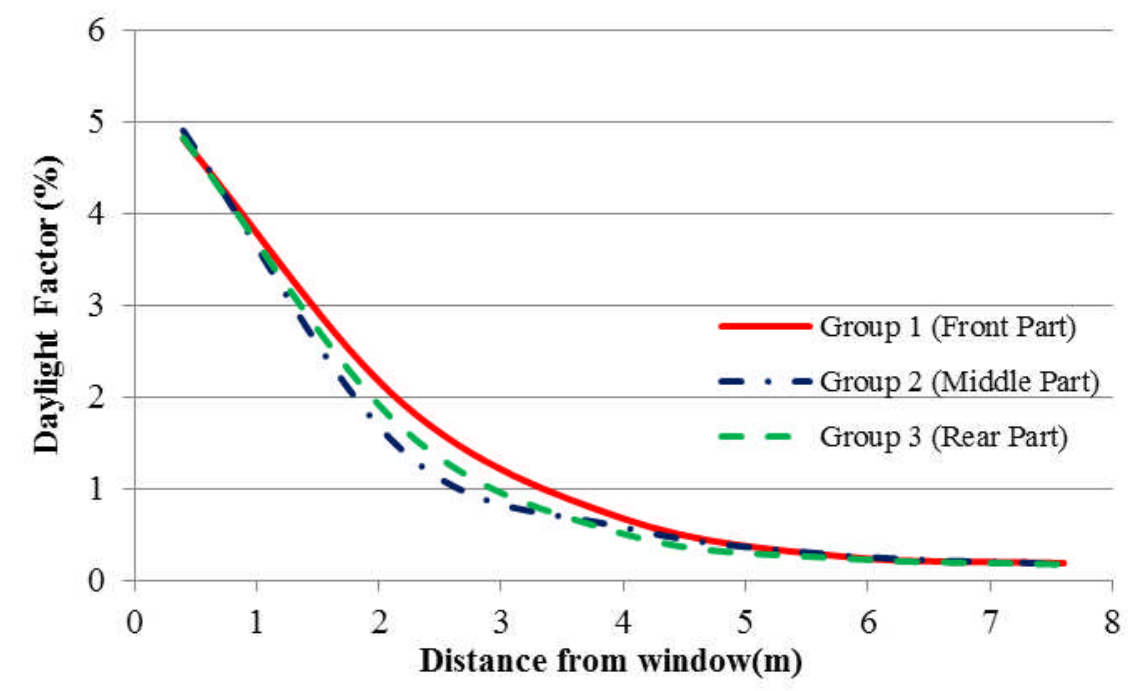

Figure 15: Measured Daylight Factor for three different part of Lecture Room 1

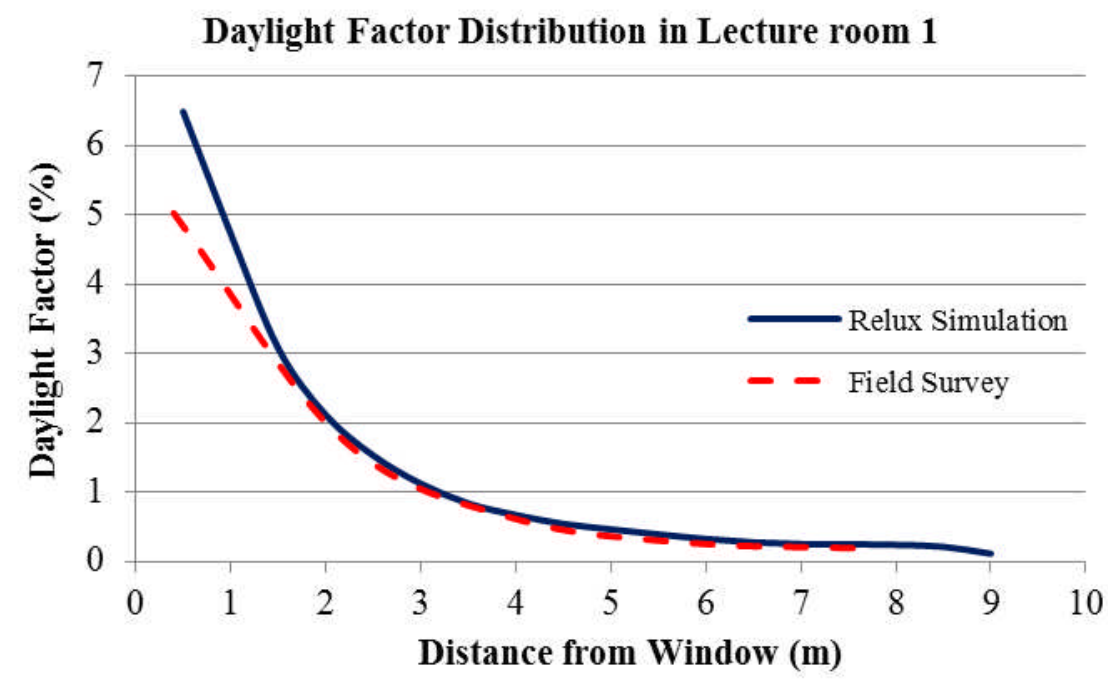

Figure 16: Comparison of daylight factor values from field survey and RELUX simulation

\subsection{Artificial lighting illuminance from simulation and measurement}

Figure 17 illustrates the simulated luminance distribution of artificial lighting in Lecture Room 1. It shows a good uniformity on the desktop level. For validation purpose, only the Lecture Room 1 is simulated here. The report generated by RELUX indicates that the average artificial lighting illuminance is 402lux, with maximum lux of 576lux, which can meet the required standard for classroom. The low illuminance level mainly occurs near the façade of the room. And the power distribution of artificial lighting is $8.96 \mathrm{~W} / \mathrm{m} 2$. 

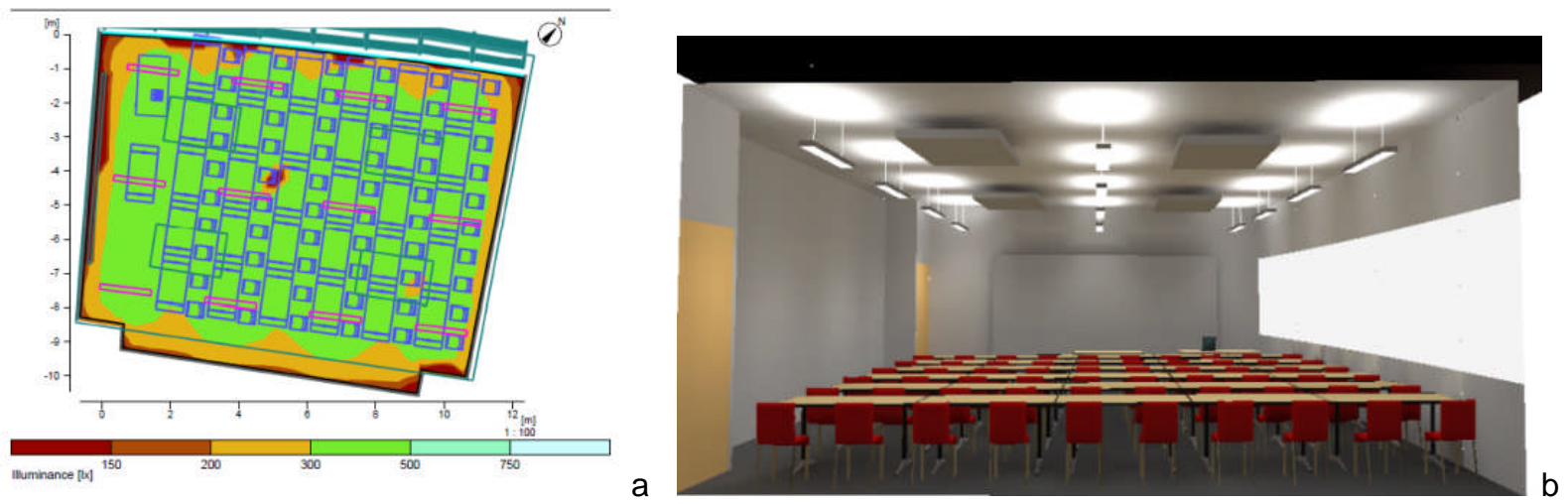

Figure 17: (a) contour lines for artificial lighting distribution, (b) rendered image of Lecture Room 1 in RELUX

For the measurement of artificial lighting illuminance distribution, Table 5 summarises the measuring results for the selected points (red dots in Figure 10) and their comparison with the simulation results were presented by bar charts in Figure 18. Both the simulation and field measurement results showed that the artificial lighting illuminance was not evenly distributed on the reference working plane. In most cases, the value from field measurement was lower than the simulated one; this might be caused by the deterioration of the luminaire in the real case. After using for a period of time, the uniformity of the luminaire had decreased, which was not considered in simulation process. However, the deviation of these two results was within the acceptable range, indicating that RELUX is reliable simulation software for artificial lighting simulation.

Table 5: Summary of artificial lighting illuminance in each selected points

\begin{tabular}{llllll}
\hline Measuring points & $\mathbf{1}$ & $\mathbf{2}$ & $\mathbf{3}$ & $\mathbf{4}$ & $\mathbf{5}$ \\
\hline Middle of light source & 531 & 471 & 635 & 466 & 578 \\
Between two light sources & 507 & 447 & 496 & 413 & 526 \\
Edge of light source & 518 & 444 & 511 & 441 & 465 \\
\hline
\end{tabular}



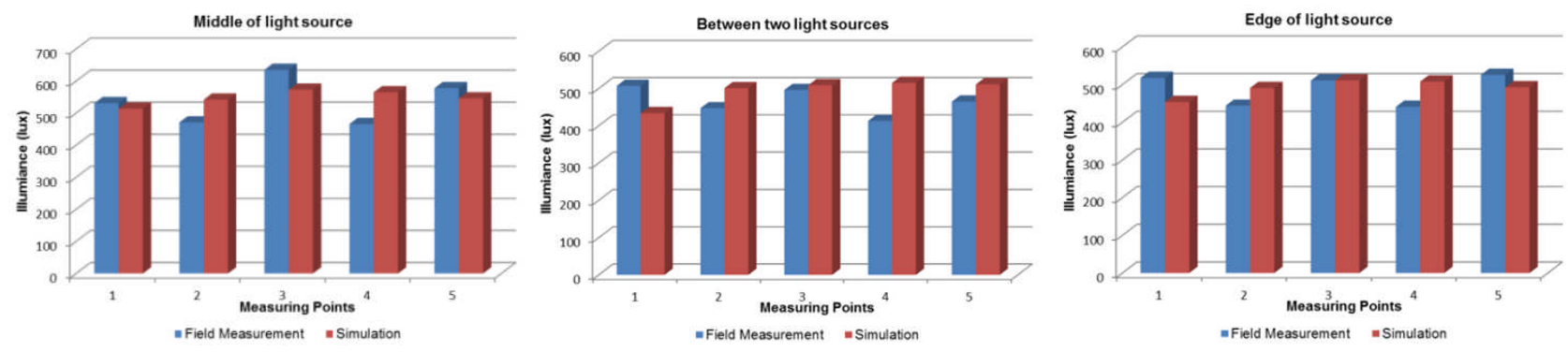

Figure 18: Comparison of field measurement and simulation of artificial lighting for different measuring points

\section{$5 \quad$ Annual Energy Saving From Daylighting}

\subsection{Methodology for estimating energy saving}

All the above works, including measuring building construction material properties, daylight factor simulation and measurement, control system investigation, are aimed to prepare for estimation of annual energy saving from daylighting with daylight-artificial lighting integration control system. Two categories of methods were used in this paper to estimate potential energy saving. The first category includes European Standard (EN15193), Daylight Factor and Daylight Coefficient method. All of them calculate the energy saving consider the daylight availability only while the second category considers the interaction with the artificial lightings. The Lecture Room 1 was selected to set an example of various calculation methods.

\subsubsection{Computational calculation using European Standard (EN15193)}

The European Standard EN15193: Energy performance of buildings — Energy requirements for lighting was devised to provide procedures for calculation of energy requirements of lightings in buildings with different functions. It also gives some numeric indicator for lighting energy requirement for certification purpose [31]. The procedure for determining the energy consumption contains lots of complex steps. However, one module in RELUX named ReluxEnergy was designed to calculate the lighting energy performance in buildings using EN15193. It converts the complex standard into a much more convenient computational program with high user-friendly interface. All the relevant information recommended in the standard such as building catalogue, artificial light specifications, daylight-related controls type, target illuminance level, etc. could be easily input into the program. Then a detailed report will be generated, including both the monthly and annually energy consumption for imported model in RELUX. The input data in ReluxEnergy for the selected 
rooms in the ESLC are listed in Table 6. It should be recommended that the ReluxEnergy has a very limited list of locations, so London was chosen as the closest location to Nottingham. The same room models as daylighting simulation in RELUX were used for energy calculation in ReluxEnergy.

Table 6: Setup for ReluxEnergy [31]

\begin{tabular}{ll}
\hline Parameter & Setting \\
\hline Location & London (Latitude: $51^{\circ}$ ) \\
Building Type & Educational Building \\
& Annual Daylight time usage: $1800 \mathrm{~h}$ \\
& Annual Non-daylight time usage: $200 \mathrm{~h}$ \\
Maintenance illuminance level & $500 l u x$ \\
Absence Factor & 0.25 (standard for educational building) \\
Controlled constant illuminance & Yes \\
Maintenance factor & 0.8 \\
Present control & Manual \\
Daylight depending control system & Daylight dependent \\
\hline
\end{tabular}

\subsubsection{Manual calculation using Daylight Factor method}

The manual calculation was based on the Daylight Factor values from the RELUX simulation, and the correlation between the daylight illuminance level and potential electrical energy saving. The following steps were taken to obtain the annual energy saving.

1) The calculation was based on the assumption that the simulated Daylight Factor values in one specific room could approximately represent the indoor and outdoor illuminance ratio for general sky condition and would remain constant for the whole year. It seems that as a penalty of simplicity, this method would have considerable loss in accuracy. The detailed evaluation of this method will be discussed later.

2) After determining the Daylight Factor value, the daylight illuminance under each artificial light luminaire could be calculated by multiplying the DF value by outdoor illuminance. EnergyPlus weather data could provide hourly outdoor illuminance for the period of one year [32]. The weather data for London was chosen as it is the nearest to Nottingham in all the available locations. 
3) According to the correlation between the daylight illuminance on working plane under artificial light and its corresponding energy saving (Equation 3), the amount of hourly energy saving for each luminaire could be calculated.

4) As the ESLC is an educational building, it was assumed that the working period is from 8:00am to $18: 00 \mathrm{pm}, 7$ days a week. Then the average monthly and annual potential energy saving can be obtained.

\subsubsection{Manual calculation using simulated Daylight Coefficient method}

The daylight coefficient method was developed by Trengenza and Waters [31]. Compared to the daylight factor method, the daylight coefficient (DC) method considers the solar position and real sky distribution and provides a more accurate method to estimate the illuminance level. As a penalty for accuracy, this method contains complex calculation process and is time consuming. Daysim, which is Radiance-based light simulation software, provides a good platform to calculate the hourly illuminance level on the selected points based on the real local climate data using the daylight coefficient method [34]. For the calculation of the potential energy saving, the hourly illuminance level obtained from the Daysim simulation replaced step 1 and 2 in DF method, the rest calculation process were kept same.

\subsubsection{Manual calculation considering artificial lighting}

Like most of the past researches for potential energy saving from daylighting, the above three methods only consider the daylight availability and simply regard the reduction of artificial light output as the ratio of daylight illuminance level under certain sensor or artificial light to the set illuminance level. There has been little attempt to consider the contribution from other artificial lights. Roisin et al. [33] developed a new calculation method, in which the artificial lighting was separated into two parts: the contribution of the luminaire above the measuring point and the contribution of other surrounding luminaires. As a result, the Equation 4 had been presented:

$E_{d l, i}(t)+\tau_{i}(t) E_{i, i}+\sum_{j=1}^{n} \tau_{j}(t) E_{j, i}=S P$

Where $\boldsymbol{E}_{\boldsymbol{d} l, \boldsymbol{i}}$ is the daylight illuminance under luminaire $\boldsymbol{i}$ at a certain time $\boldsymbol{t}$, which can be calculated; $\boldsymbol{\tau}_{\boldsymbol{i}}$ is the light output fraction of luminaire $\boldsymbol{i} ; \boldsymbol{E}_{\boldsymbol{i} \boldsymbol{i}}$ is the illuminance under luminaire $\boldsymbol{i} ; \boldsymbol{\tau}_{\boldsymbol{j}}$ is the light 
output fraction of luminaire $\boldsymbol{j} ; \boldsymbol{E}_{\boldsymbol{j}, \boldsymbol{i}}$ illuminance contribution from luminaire $\boldsymbol{j}$ to position $\boldsymbol{i} ; \boldsymbol{n}$ is the number of other luminaires; $\boldsymbol{S P}$ is the set illuminance level.

In the case of Lecture Room 1 in the ESLC, the hourly data of $\boldsymbol{E}_{d l i}(\boldsymbol{t})$ could be obtained either by DF method or DC method, $\boldsymbol{E}_{\boldsymbol{i}, \boldsymbol{i}}$ and $\boldsymbol{E}_{\boldsymbol{j} \boldsymbol{i}}$ were achievable with RELUX. There are totally 12 luminaries in the room; each luminaire can get one equation as given by Equation 4. Therefore, these 12 equations could be solved and get 12 lighting output ratios under certain illuminance level. These lighting output ratios can be converted into energy saving using Equation 3.

\subsection{Results and discussion}

The results for monthly and annual energy saving potential from daylighting using various calculation methods are shown in Table 7 and Figure 19. The main trends for monthly saving potential throughout the year were similar: more energy saving can be achieved in summer than winter. It is likely due to the seasonal difference in daylight period and solar altitude as well; the summer always has longer and higher daylight availability for UK. Moreover, the annual energy saving results using DF or DC method only were lower than those considering contribution of other artificial lighting luminaires. The energy saving potential could reach as high as $46 \%$ using DC method if the interaction between artificial lightings were counted; this value reduced to $40 \%$ if the DF method was used. This variation mainly comes from the different ways of predicting hourly illuminance level, the DF method tends to be a static climate-based evaluation which assumed that the ratio of internal illuminance to the external illuminance were kept same, while the DC method suggested this ratio was dynamic and would change according to different sun positions and sky distribution. Clearly, the DC method is more representative to the reality; however, it should be emphasised that using the DC method may overestimate the potential energy saving if the user behaviour is taken into consideration. Under some sunny weather condition, the indoor illuminance level might be extremely high, which would cause overheating and glare near the window and prevent the room occupants from using daylighting. In this case, the room occupants prefer to lower the blinds or close the curtain and switch to artificial lighting instead. In comparison, the DF method may underestimate the daylight availability using a constant daylight factor value for other sky 
conditions and could be regarded as the worst case for energy consumption. Therefore, the predicted annual energy saving potential could be between $40-46 \%$ in this selected room.

Table 7: Summary of annual energy saving by various estimation methods

\begin{tabular}{ll}
\hline Calculation method & Saving value \\
\hline European Standard EN15193 (ReluxEnergy) & $35.40 \%$ \\
Daylight Factor Method (manual calculation) & $32.40 \%$ \\
Daylight Coefficient Method & $40.37 \%$ \\
Daylight Factor Method considering artificial lighting distribution & $40.30 \%$ \\
Daylight Coefficient Method considering artificial lighting distribution & $46.34 \%$ \\
\hline
\end{tabular}

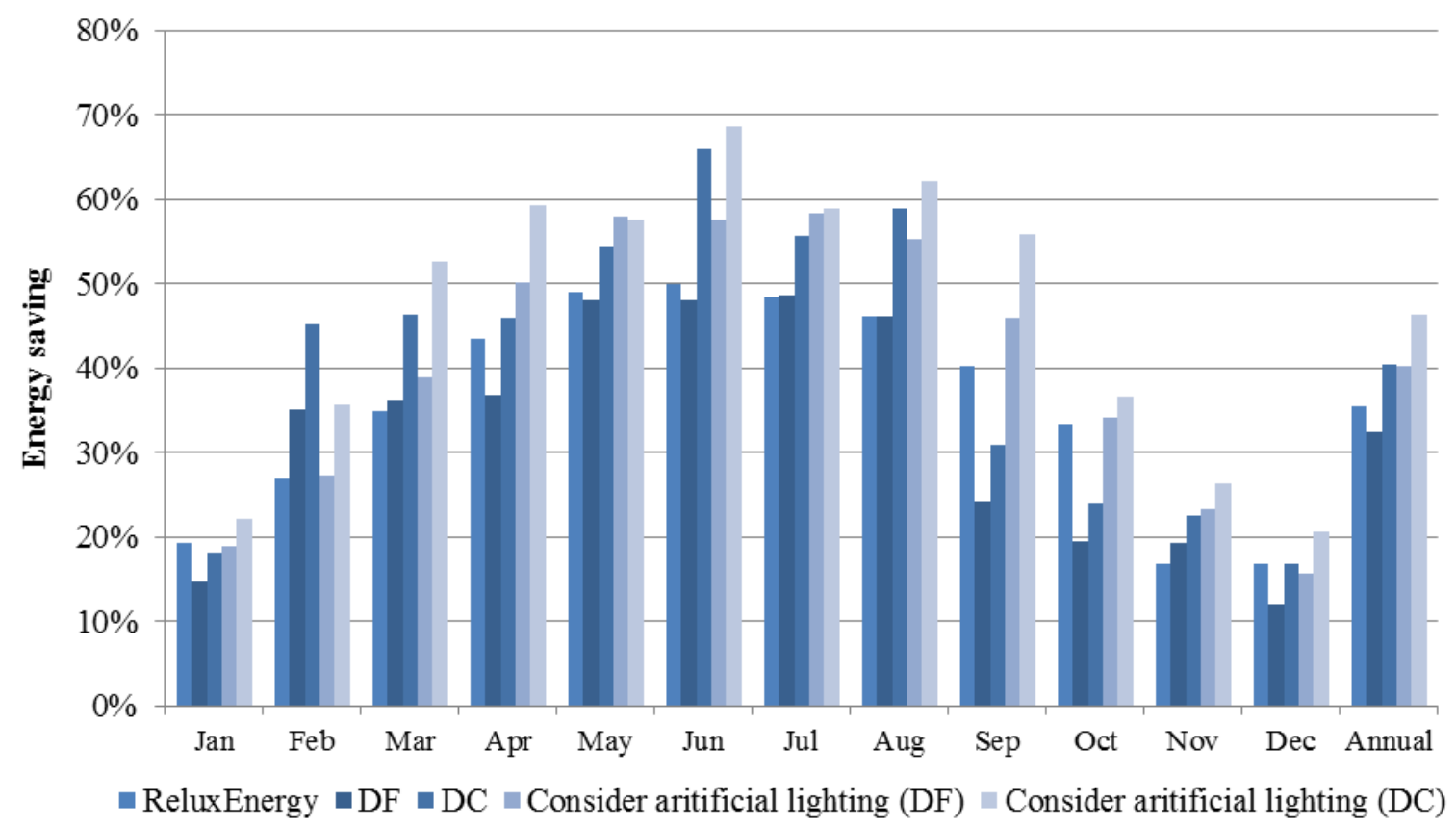

Figure 19: Monthly and annual potential energy saving from daylighting using various estimation methods

\section{Conclusions}

In order to estimate daylighting induced energy saving in the Engineering and Science Learning Centre (ESLC) in the University of Nottingham, the daylighting and artificial lighting distribution in four typical side-lit rooms has been investigated using the lighting analysis software RELUX. Validation of RELUX simulation has also been conducted through comparison with field 
measurement. Previous studies indicated that the estimation of room optical characteristics can cause errors in daylighting simulation. In order to provide reliable input parameters for simulation, this paper has presented a novel, simple and economical method to measure the window transmittance and surface reflectance of room construction with the help of photometric integrating box. The deviation of the results between simulation and field measurement is within $20 \%$, which is generally acceptable in lighting simulation. The difference may be caused by the estimation error for reflectance of surrounding buildings, some unavoidable error during field measurements and errors for the measuring equipment. In general, RELUX seems to be valid lighting simulation software for both daylighting and artificial lighting analysis.

Another point of importance of this paper is that, the daylighting induced energy saving potential of artificial lighting with high frequency dimming control has been estimated in one typical side-lit room. This has been achieved by the employment of various energy saving estimation methods, including using European Standard EN15193, Daylight Factor (DF) and Daylight Coefficient (DC) methods with or without considering influence of artificial lighting. The result shows that the results when considering artificial lighting is higher than those consider the daylight availability only. The European Standard EN15193 gives 35\% of energy saving potential, whereas the potential energy saving is estimated to be as high as $46 \%$ using the DC method and $40 \%$ for the DF method when the artificial lighting distribution is considered. These values may represent the situation between the best and worst potential energy saving scenarios, as the DC method does not consider the overheating and glare problem while the DF method uses a constant daylight factor to estimate daylight availability for the whole year. Therefore, the annually potential energy saving from daylighting could lie between $40-46 \%$.

However, the energy saving by occupancy control and the user behavior is not numerically analyzed. Roisin's study shows that the occupation rate has great influence on energy saving, but not linearly due to the time delay [31]. Meanwhile, the IESNA Lighting Handbook acknowledge that the energy saving from daylight is influenced by the occupants' activities as well as their attitude and training [32]. Further work could be done to investigate how these two factors can influence the potential energy saving from daylighting. 


\section{REFERENCE}

[1] Ran Yi, Li Shao, Yuehong Su, Saffa Riffat: Daylighting performance of atriums in subtropical climate. International Journal Low-Carbon Technology 2009, 4(4):230-237.

[2] Krarti M, Erickson PM, Hillman TC: A simplified method to estimate energy savings of artificial lighting use from daylighting. Building and Environment 2005, 40(6):747-754.

[3] Li DHW, Wong SL: Daylighting and energy implications due to shading effects from nearby buildings. Applied Energy 2007, 84(12):1199-1209.

[4] Ihm P, Nemri A, Krarti M: Estimation of lighting energy savings from daylighting. Building and Environment 2009, 44(3):509-514.

[5] Bellegem.V: Increased energy savings by individual light control. Proceedings of Right Light 1997, 4:179-182.

[6] Enedir Ghisi, John A. Tiker: Evaluating the potential of energy savings on lighting by integrating fibre optics in buildings. Building and Environment 2006, 41(12):1611-1621.

[7] Ghisi E, Tinker JA: Evaluating the potential for energy savings on lighting by integrating fibre optics in buildings. Building and Environment 2006, 41(12):1611-1621.

[8] Doulos L. TAaTF: Quantifying energy savings in daylight responsive systems: the role of dimming electronic ballasts. Energy and Building 2008, 40(1):36-50.

[9] Li DHW, Lam TNT, Wong SL: Lighting and energy performance for an office using high frequency dimming controls. Energy Conversion and Management 2006, 47(9-10):1133-1145.

[10] Li DHW, Lam JC: Evaluation of lighting performance in office buildings with daylighting controls. Energy and Buildings 2001, 33(8):793-803.

[11] Li DHW, Lam TNT, Wong SL, Tsang EKW: Lighting and cooling energy consumption in an open-plan office using solar film coating. Energy 2008, 33(8):1288-1297.

[12] Bodart M, De Herde A: Global energy savings in offices buildings by the use of daylighting. Energy and Buildings 2002, 34(5):421-429.

[13] Carlos E. Ochoa MBCAJLMH: State of the art in lighting simulation for building science: a literature review. Journal of Building Performance Simulation 2012, 5(4):209-233.

[14] Li DHW: A review of daylight illuminance determinations and energy implications. Applied Energy 2010, 87(7):2109-2118.

[15] Reinhart C, Fitz A: Findings from a survey on the current use of daylight simulations in building design. Energy and Buildings 2006, 38(7):824-835.

[16] Kim C-S, Chung S-J: Daylighting simulation as an architectural design process in museums installed with toplights. Building and Environment 2011, 46(1):210-222.

[17] Ng EY-Y, Poh LK, Wei W, Nagakura T: Advanced lighting simulation in architectural design in the tropics. Automation in Construction 2001, 10(3):365-379.

[18] Li D-L, CCS - Lam, JC: Predicting daylight illuminance by computer simulation techniques. Lighting Research and Technology 2004, 36(2):113-129. 
[19] Mardaljevic J: Verification of program accuracy for illuminance modelling: assumptions, methodology and an examination of conflicting findings. Lighting Research and Technology 2004, 36(3):217-242.

[20] Maamari F, Fontoynont M, Adra N: Application of the CIE test cases to assess the accuracy of lighting computer programs. Energy and Buildings 2006, 38(7):869-877.

[21] Estate office, University of Nottingham, UK Avail at: [http://www.nottingham.ac.uk/estates/developments/recentdevelopments.aspx]

[22] Callow J: Daylighting Using Tubular Light Guide Systems. PhD Thesis. University of Nottingham; 2003.

[23] Information about Relux Avail at [http://www.relux.biz]

[24] McMullan R: Environmental Science in Building, Sixth Edition edn. New York: PALGRAVE MACMILLAN; 2007.

[25] CIBSE Guide A: Environmental Design; 2006.

[26] Littlefair P: Selecting lighting controls. In. Garston: IHS BRE Press; 2006.

[27] Li DHW, Cheung KL, Wong SL, Lam TNT: An analysis of energy-efficient light fittings and lighting controls. Applied Energy 2010, 87(2):558-567.

[28] CIBSE Concise Handbook. In. London; 2008.

[29] Reinhart CF, Andersen M: Development and validation of a Radiance model for a translucent panel. Energy and Buildings 2006, 38(7):890-904.

[30] Galasiu AD, Atif MR: Applicability of daylighting computer modeling in real case studies: comparison between measured and simulated daylight availability and lighting consumption. Building and Environment 2002, 37(4):363-377.

[31] EN 15193: Energy performance of buildings: Energy requirements for lighting. British Standards Institution; 30 November 2007.

[32] Weather Data [http://apps1.eere.energy.gov/buildings/energyplus/cfm/weather_data.cfm]

[33] Roisin B, Bodart M, Deneyer A, D'Herdt P: Lighting energy savings in offices using different control systems and their real consumption. Energy and Buildings 2008, 40(4):514523.

[34] Reinhart CF, Wienold J: The daylighting dashboard - A simulation-based design analysis for daylit spaces. Building and Environment 2011, 46(2):386-396.

[35] Christoph F R: Lightswitch-2002: a model for manual and automated control of electric lighting and blinds. Solar Energy 2004, 77(1):15-28. 